\title{
Erratum to: Social signals increase monoamine levels in the tegmentum of juvenile Mexican spadefoot toads (Spea multiplicata)
}

Verónica G. Rodriguez Moncalvo •

Sabrina S. Burmeister • Karin S. Pfennig

Published online: 19 June 2013

(c) Springer-Verlag Berlin Heidelberg 2013

Erratum to: J Comp Physiol A

DOI 10.1007/s00359-013-0826-6

In the original publication, the family name of the first author was incorrectly published as Moncalvo. The correct family name of the author is Rodriguez Moncalvo.

The online version of the original article can be found under doi:10.1007/s00359-013-0826-6.

V. G. Rodriguez Moncalvo - S. S. Burmeister - K. S. Pfennig Department of Biology, University of North Carolina at Chapel Hill, Chapel Hill, NC 27599-3280, USA

Present Address:

V. G. Rodriguez Moncalvo

Department of Biomedical Sciences, University of Guelph,

Guelph, ON N1G 2W1, Canada

\section{S. S. Burmeister ( $\square)$}

Curriculum in Neurobiology, University of North Carolina at Chapel Hill, Chapel Hill, NC 27599-3280, USA

e-mail: sburmeister@unc.edu 